\title{
“The Esophageal Cooling Device": A New Way to Achieve Targeted Temperature Management
}

\author{
Marvin Wayne* \\ Associate Clinical Professor, University of Washington, USA
}

Submission: February 19, 2017; Published: April 28, 2017

*Corresponding author: Marvin Wayne, Associate Clinical Professor, University of Washington, Bellingham, WA 1800 Broadway, USA, Tel: 360-778-8454; Email: mwayne@cob.org

\section{Abstract}

Targeted temperature management (TTM) is a standard of care following cardiac arrest, but the therapy is often underutilized. Workflow interruptions and adverse events associated with existing TTM devices contribute to underutilization, which has prompted the development of new technologies. The purpose of this article is to summarize the rationale behind evaluating a new TTM device, the Esophageal Cooling Device (ECD).

Keywords: Targeted temperature management; Therapeutic hypothermia; Post cardiac arrest; Emergency room; Innovation adoption; Resuscitation protocols

\section{Introduction}

Targeted temperature management (TTM) has become a standard of care following cardiac arrest $[1,2]$ and the benefits of this therapy are well established [3,4]. However, not all patients who should receive this therapy do. Studies have documented TTM under utilization at the hospital level $[5,6]$ but have not extensively documented why some facilities fail to initiate TTM for some patients or never fully implement a TTM protocol at all. Given that TTM was first included in the American Heart Association Guidelines in 2005, ignorance of the practice is an unlikely explanation. Closer examination of the current technologies used to deliver TTM provides an alternative reason for underutilization.

Over the last decade, advanced TTM systems (i.e., those that incorporate servo-controlled temperature monitoring to automatically adjust therapy to patient needs) used one of two methods to affect heat transfer for cooling: intravascular convection and surface conduction. Intravascular methods use specially designed catheters that are inserted into the central venous system. This method promotes efficient heat transfer but patients are at risk of developing blood stream infections and blood clots [7,8] and TTM initiation can be significantly delayed, sometimes for hours, when a physician is not available to place the line. Surface devices use pads or blankets to cover the patient and transfer heat through the skin. This configuration is non-invasive, but it is also less efficient. Surface cooling is associated with skin damage $[9,10]$ and patient access is obscured. To place most surface devices, 2-3 nurses must work together to manipulate the patient and then must ensure that the device remains clean throughout the course of treatment. Thus, while there are several devices available to clinicians to effectively perform TTM, there is also an opportunity for improvement. This in turn has inspired the development of new technologies that are now available for implementation, either in conjunction with, or as a replacement for, existing TTM methods.

\section{Evaluating a New TTM Device}

One such technology, the Esophageal Cooling Device (ECD; Advanced Cooling Therapy, Inc., Chicago, IL) was approved for marketing by the FDA in 2015. At that time, Peace Health St. Joseph Medical Center in Bellingham, WA, had successfully cooled over 700 PCA patients using a surface method. Patient outcomes were consistent with the literature; approximately $51 \%$ of patients were discharged from the ICU with good neurological outcomes, as measured by the modified Rankin Scale (mRS). However, the blanket-style system obscured patient access and sometimes interfered with nursing care. 


\section{Journal of Cardiology \& Cardiovascular Therapy}

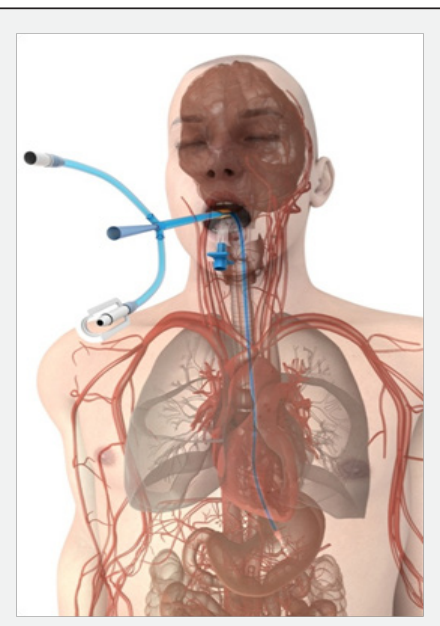

Figure 1: The ECD (highlighted in blue) is placed in the esophagus and replaces a standard OG tube. Two outer lumens circulate water provided by an external heat exchanger and a central lumen connects to the suction canister.

The Department of Emergency Medicine evaluated the ECD on two key criteria: 1) that the clinical performance of the ECD was equivalent to the surface system in use, and 2) that staff members experienced less interference with clinical tasks. Results from published pre-clinical data [11-14], case studies [15-18], and prospective clinical evaluations [19] suggested that equivalent performance was attainable. The internal placement of the device, which replaces a standard OG tube (Figure 1), also suggested that reduced interference with clinical tasks was likely.

\section{Discussion}

At the time of this writing, the Emergency Department Cardiac Cath Lab, and ICU have used the ECD to deliver TTM to 30 consecutive patients. The ECDs were placed by ER, ICU, and STAT nurses, who expressed satisfaction with the training burden required to demonstrate competence for correct insertion and use. The ECD connects to the same heat exchange unit that was already in use in the department (Blanketrol III, Cincinnati Sub-Zero, Cincinnati, OH), which helped accelerate the learning curve. In some instances, simple modifications were employed, such as restricting water outflow to make the device more rigid during placement or briefly deflating the ET tube balloon, for challenging insertions. Clinical staff members observed a rapid start to cooling (typically slightly over $\left.1^{\circ} \mathrm{C} / \mathrm{hr}\right)$ and stable maintenance temperatures $\left( \pm 1^{\circ} \mathrm{C}\right.$ from target) throughout treatment, consistent with other clinical performance evaluations [20]. Nurses were also pleased with the flexibility the ECD offered, as cooling blankets could be added or removed as needed to best meet evolving patient needs during TTM. In addition, cardiologists responded favorably to the ECD because it caused almost no distortion in the catheterization laboratory. One shortcoming of the ECD is that it does not currently support feeding through the central lumen, though this feature will be included in future iterations [21].

\section{Conclusion}

TTM is a well-established but often underutilized therapy that is highly beneficial for post-cardiac arrest patients. Workflow interruptions and adverse events associated with existing TTM devices contribute to underutilization, which has prompted the development of new technologies. However, the decision to modify an already successful TTM protocol should not be taken lightly. For the ECD, the combination of published clinical data and elements of the device design suggested an opportunity for improvement in the department's practice and the outcomes of an evaluation suggest that the ECD is a worthy addition to the post-resuscitation TTM protocols available to the emergency department.

\section{References}

1. Callaway CW, Donnino MW, Fink EL, Geocadin RG, Golan E, et al. (2015) Part 8: Post-Cardiac Arrest Care: 2015 American Heart Association Guidelines Update for Cardiopulmonary Resuscitation and Emergency Cardiovascular Care. Circulation 132(18 Suppl 2): S465-S482.

2. Nolan JP, Soar J, Cariou A, Cronberg T, Moulaert VRM, et al. (2015) European Resuscitation Council and European Society of Intensive Care Medicine 2015 Guidelines for Post-resuscitation Care. Intensive Care Med 41(12): 2039-2056.

3. Bernard SA, Gray TW, Buist MD, Jones BM, Silvester W, et al. (2002) Treatment of Comatose Survivors of Out-of-Hospital Cardiac Arrest with Induced Hypothermia. N Engl J Med 346(8): 557-563.

4. Hypothermia after Cardiac Arrest Study Group (2002) Mild Therapeutic Hypothermia to Improve the Neurologic Outcome after Cardiac Arrest. N Engl J Med 346(8): 549-556.

5. Patel PV, John S, Garg RK, Temes RE, Bleck TP, et al. (2011) Therapeutic Hypothermia after Cardiac Arrest is Underutilized in the United States. Ther Hypothermia Temp Manag 1(4): 199-203.

6. Majersik JJ, Silbergleit R, Meurer WJ, Brown DL, Lisabeth LD, et al. (2008) Public Health Impact of Full Implementation of Therapeutic Hypothermia after Cardiac Arrest. Resuscitation 77(2): 189-194.

7. Reccius A, Mercado P, Vargas P, Canals C, Montes J (2015) Inferior Vena Cava Thrombosis Related to Hypothermia Catheter: Report of 20 Consecutive Cases. Neurocrit Care 23(1): 72-77.

8. Smith JW, Egger M, Franklin G, Harbrecht B, Richardson JD (2011) Central Line-Associated Blood Stream Infection in the Critically Ill Trauma Patient. Am Surg 77(8): 1038-1042.

9. Jarrah S, Dziodzio J, Lord C, Fraser GL, Lucas L, et al. (2011) Surface Cooling after Cardiac Arrest: Effectiveness, Skin Safety, and Adverse Events in Routine Clinical Practice. Neurocrit Care 14(3): 382-388.

10. Liu YM, Ibrahim A, Jan T, Chang P, Fagan S, et al. (2014) Skin Necrosis as a Complication of Therapeutic Hypothermia. J Burn Care Res 35(3): e184-e186.

11. Kulstad E, Courtney DM, Waller D (2012) Induction of Therapeutic Hypothermia via the Esophagus: a Proof of Concept Study. World J Emerg Med 3(2): 118-122.

12. Kulstad E, Metzger AK, Courtney DM, Rees J, Shanley P, et al. (2013) Induction, Maintenance, and Reversal of Therapeutic Hypothermia with an Esophageal Heat Transfer Device. Resuscitation 84(11): 16191624.

13. Kulstad EB, Naiman M, Shanley P, Garrett F, Haryu T, et al. (2015) Temperature Modulation with an Esophageal Heat Transfer Device-a Pediatric Swine Model Study. BMC Anesthesiol 15: 16. 
14. Vaicys V, Eason A, Schieber JD, Kulstad EB (2012) Therapeutic Hypothermia Induction via an Esophageal Route--a Computer Simulation. Am J Emerg Med 30(6): 932-935.

15. Hegazy A, Lapierre D, Althenayan E (2015) Targeted Temperature Management after Cardiac Arrest and Fever Control with an Esophageal Cooling Device. Crit Care 19(Suppl 1): P424.

16. Hegazy AF, Lapierre DM, Butler R, Althenayan E (2015) Temperature Control in Critically Ill Patients with a Novel Esophageal Cooling Device: A Case Series. BMC Anesthesiol 15: 152.

17. Markota A, Fluher J, Balazic P, Kit B, Sinkovic A (2015) Therapeutic Hypothermia with Esophageal Heat Transfer Device. Resuscitation 96(Suppl 1): 138

This work is licensed under Creative Commons Attribution 4.0 License

DOI: $10.19080 /$ JOCCT.2017.05.555651
18. Markota A, Kit B, Fluher J, Sinkovic A (2015) Use of an Oesophageal Heat Transfer Device in Therapeutic Hypothermia. Resuscitation 89: e1-e2.

19. Markota A, Fluher J, Kit B, Balažič P, Sinkovič A (2016) The Introduction of an Esophageal Heat Transfer Device into a Therapeutic Hypothermia Protocol: A Prospective Evaluation. Am J Emerg Med 34(4): 741-745.

20. Naiman M, Markota A, Hegazy AF, Dingley J, Kulstad E (2017) Temperature Management in Critical Care and Burn Patients using an Esophageal Heat Transfer Device. Mil Med, In Press, USA.

21. Naiman M, Shanley P, Garrett F, Kulstad E (2016) Evaluation of Advanced Cooling Therapy's Esophageal Cooling Device for Core Temperature Control. Expert Rev Med Devices 13(5): 423-433.

Your next submission with Juniper Publishers will reach you the below assets

- Quality Editorial service

- Swift Peer Review

- Reprints availability

- E-prints Service

- Manuscript Podcast for convenient understanding

- Global attainment for your research

- Manuscript accessibility in different formats

( Pdf, E-pub, Full Text, Audio)

- Unceasing customer service

Track the below URL for one-step submission https://juniperpublishers.com/online-submission.php 